\title{
CITED2 and NCOR2 in anti-oestrogen resistance and progression of breast cancer
}

\section{T van Agthoven', AM Sieuwerts², J Veldscholte', ME Meijer-van Gelder², M Smid ${ }^{2,3}$, A Brinkman', AT den Dekker', IM Leroy', WFJ van IJcken ${ }^{4}$, S Sleijfer', JA Foekens ${ }^{2,3}$ and LCJ Dorssers*,I}

'Department of Pathology, Erasmus MC - University Medical Center Rotterdam, Rotterdam 3000 CA, The Netherlands; ${ }^{2}$ Department of Medical Oncology, Erasmus MC - University Medical Center Rotterdam, Rotterdam 3000 CA, The Netherlands; ${ }^{3}$ Cancer Genomics Center, Erasmus MC - University Medical Center Rotterdam, Rotterdam 3000 CA, The Netherlands; ${ }^{4}$ Erasmus Center of Biomics, Erasmus MC - University Medical Center Rotterdam, Rotterdam 3000 CA, The Netherlands

BACKGROUND: Endocrine therapies of breast cancer are effective but ultimately fail because of the development of treatment resistance. We have previously revealed several genes leading to tamoxifen resistance in vitro by retroviral insertion mutagenesis. To understand the manner in which these genes yield tamoxifen resistance, their effects on global gene expression were studied and those genes resulting in a distinct gene expression profile were further investigated for their clinical relevance.

METHODS: Gene expression profiles of 69 human breast cancer cell lines that were made tamoxifen resistant through retroviral insertion mutagenesis were obtained using oligonucleotide arrays and analysed with bioinformatic tools. mRNA levels of NCOR2 and CITED2 in oestrogen receptor-positive breast tumours were determined by quantitative RT-PCR. mRNA levels were evaluated for association with metastasis-free survival (MFS) in 620 patients with lymph node-negative primary breast cancer who did not receive systemic adjuvant therapy, and with clinical benefit in 296 patients receiving tamoxifen therapy for recurrent breast cancer.

RESULTS: MRNA expression profiles of most tamoxifen-resistant cell lines were strikingly similar, except for the subgroups of cell lines in which NCOR2 or CITED2 were targeted by the retrovirus. Both NCOR2 and CITED2 mRNA levels were associated with MFS, that is, tumour aggressiveness, independently of traditional prognostic factors. In addition, high CITED2 mRNA levels were predictive for a clinical benefit from first-line tamoxifen treatment in patients with advanced disease.

CONCLUSIONS: Most retrovirally targeted genes yielding tamoxifen resistance in our cell lines do not impose a distinctive expression profile, suggesting that their causative role in cell growth may be accomplished by post-transcriptional processes. The associations of NCOR2 and CITED2 with outcome in oestrogen receptor-positive breast cancer patients underscore the clinical relevance of functional genetic screens to better understand disease progression, which may ultimately lead to the development of improved treatment options.

British Journal of Cancer (2009) I I I, I824- 1832. doi: I0.1038/sj.bjc.6605423 www.bjcancer.com

Published online 10 November 2009

(C) 2009 Cancer Research UK

Keywords: tamoxifen; drug resistance; functional screen; insertion mutagenesis; gene expression profile; prognostic and predictive markers

Tamoxifen is widely applied in the treatment of breast cancer. Its efficacy has been established in both the adjuvant setting to reduce recurrences in localised disease (Early Breast Cancer Trialists' Collaborative Group, 2005) and in the palliative management of patients with advanced disease (Jaiyesimi et al, 1995; Jordan, 1995; Osborne, 1998). In agreement with its biological function as an anti-oestrogen, tamoxifen requires the presence of the oestrogen receptor (ER) alpha. But a substantial number of ER $\alpha$ positive breast cancer patients will not benefit from tamoxifen treatment because of intrinsic or de novo resistance. Furthermore, nearly all responsive patients will experience disease progression

* Correspondence: Dr LC) Dorssers, Department of Pathology, Josephine Nefkens Institute, Be432, Erasmus MC, PO Box 2040, Rotterdam 3000 CA, The Netherlands; E-mail: I.dorssers@erasmusmc.nl

Received 16 June 2009; revised 8 October 2009; accepted 12 October 2009; published online 10 November 2009 because of the development of acquired resistance. Although other anti-oestrogens and aromatase inhibitors have been developed, resistance to these compounds will occur (Nabholtz et al, 2000; Mouridsen et al, 2003; Paridaens et al, 2003; Howell, 2006). Despite intense research in the last few decades into the failure of endocrine therapies (Ali and Coombes, 2002; Clarke et al, 2003; Jansen et al, 2005; Osborne et al, 2005; Riggins et al, 2007; Creighton et al, 2008; Hurtado et al, 2008; Iorns et al, 2008), more insight into the underlying mechanisms is definitely needed.

Previously, we executed a non-biased functional genetic screen in an oestrogen-dependent human breast cancer cell model, aimed at identifying genes causing tamoxifen resistance. Insertion of a defective retrovirus into the genome randomly introduced individual genetic changes in ZR-75-1 cells (Dorssers et al, 1993). Infected cells were then selected for their ability to proliferate while being exposed to tamoxifen. From these cultures, 79 stable cell lines were established. Using various molecular 
strategies, common virus insertion sites (cVIS) were mapped, enabling the identification of candidate genes that cause the resistant phenotype. These retroviral targets were collectively termed breast cancer anti-oestrogen-resistance $(B C A R)$ genes. Ultimate proof for the role of seven target genes (AKT1, $A K T 2$, $B C A R 1, B C A R 3, E G F R, G R B 7$ and TRERF1) was obtained by cDNA transfection into oestrogen-dependent cancer cells, transforming them into a tamoxifen-resistant phenotype (Van Agthoven et al, 1998, 2009b; Brinkman et al, 2000).

To elucidate the manner in which these retroviral target genes induce tamoxifen resistance in ZR-75-1 cells, we assessed whether differences in gene expression patterns existed between the different groups of tamoxifen-resistant cell lines. Two candidate target genes, CITED2 and NCOR2, yielding distinct gene expression profiles when compared with other cell lines, were analysed for their clinical relevance in terms of tamoxifen resistance and tumour aggressiveness.

\section{MATERIALS AND METHODS}

\section{Cell culture}

The panel of tamoxifen-resistant cell lines was previously generated by retrovirus infection and selection for resistance to 4-hydroxy-tamoxifen (OH-Tam, Sigma-Aldrich Chemie BV, Zwijndrecht, The Netherlands) (Dorssers et al, 1993). Cell lines were cultured in RPMI supplemented with $15 \%$ bovine calf serum, $10 \%$ CRIP supernatant and $1 \mu \mathrm{M}$ of $\mathrm{OH}-\mathrm{Tam}$ as described before (Dorssers et al, 1993).

\section{Gene expression profiling}

Total RNA was prepared by direct lysis with RNA-Bee (Bioconnect, Huissen, The Netherlands) of approximately $80 \%$ confluent cells. cDNA synthesis was performed using an T7dToligo primer, $3 \mu \mathrm{g}$ of total RNA and reverse transcriptase (Superscript II, Invitrogen, Breda, The Netherlands). Second-strand synthesis was carried out by E.coli ligase, E.coli DNA polymerase (Invitrogen) and RNase H (Promega Benelux b.v., Leiden, The Netherlands). The double-stranded cDNA was purified on Quiaquick PCR columns (Qiagen, Hilden, Germany). In vitro transcription using the T7 Megascript Kit (Ambion, Austin, TX, USA) was used to produce amplified RNA (aRNA). Further details are presented in the Supplementary information.

Spotted oligo microarrays with the Operon V3.0 library $(35 \mathrm{~K}$ Human, http://omad.operon.com/humanV3) were obtained from the Netherlands Cancer Institute Central Microarray Facility (NKI$\mathrm{CMF}$ ). Protocols for sample preparation were taken from the NKICMF website (http://microarrays.nki.nl) and are detailed elsewhere (Meester-Smoor et al, 2008). In short, $1 \mu \mathrm{g}$ of amplified RNA was labelled using the ULS-Cy3/5 aRNA fluorescent labelling kit (Kreatech, Amsterdam, The Netherlands), and was used for hybridisation (Supplementary information). Two independent samples of a cell line were hybridised against the reference and one of them was also used in a dye-swap hybridisation. Hybridised arrays were scanned on a ScanArray Express HT instrument (Perkin Elmer Life and Analytical Sciences BV, Groningen, The Netherlands). Fluorescence intensities were determined using ImaGene software version 6.0 (Biodiscovery, El Segundo, CA, USA), uploaded into the CMF database (CMFdb, http:// cmfdb.nki.nl) and normalised using the lowess subarray method. Both raw and normalised data have been deposited in NCBI's Gene Expression Omnibus (Edgar et al, 2002) and are accessible through GEO Series accession number GSE14513 (http://www.ncbi.nlm. nih.gov/geo/query/acc.cgi?acc = GSE14513).

Analyses on normalised data were performed using BRBArrayTools developed by Dr Richard Simon and the BRB-ArrayTools
Development Team (http://linus.nci.nih.gov/BRB-ArrayTools.html). Supervised class comparisons (Supplementary information and Supplementary Table S1) were performed to select genes with differential expression in cell lines grouped according to the presence of the retrovirus in a particular cVIS (Van Agthoven et al, 2009b). Hierarchical clustering was carried out with Spotfire DecisionSite 9.0 (Tibco, Somerville, MA, USA). To analyse selected genes in human breast cancer microarray data (Wang et al, 2005), spots were linked to Affymetrix probe sets using Entrez Gene and Ensemble identifiers (Supplementary Table S2).

\section{Patient samples}

The protocol to study biological markers associated with disease outcome was approved by the medical ethics committee of the Erasmus Medical Center Rotterdam, The Netherlands (MEC 02.953). This retrospective study used 791 blindly coded, ER $\alpha$ protein-positive ( $\geqslant 10 \mathrm{fmol} / \mathrm{mg}$ of protein) primary tumour tissues, in accordance with the Code of Conduct of the Federation of Medical Scientific Societies in the Netherlands (http:// www.fmvv.nl). This report is as much as possible in line with the REMARK guidelines (McShane et al, 2006). Primary breast tumours were obtained from patients with detailed clinical follow-up as previously described (Sieuwerts et al, 2006, 2007; Jansen et al, 2007; Meijer et al, 2008, 2009; Van Agthoven et al, 2009a). All patients underwent breast surgery for breast cancer from 1978 through $2000 . \mathrm{ER} \alpha$ status was determined by routine ligand-binding assays or by enzyme immunoassays (Foekens et al, 1989). Further patient characteristics are summarised in Supplementary Table S3.

To evaluate the impact of individual genes on tamoxifen resistance, 296 patients who received tamoxifen monotherapy as first-line treatment for advanced disease were included (Sieuwerts et al, 2005). Of these patients, $10 \%$ presented with distant metastasis at diagnosis (Supplementary Table S3). None of these patients $(43 \%$ node negative) had received prior adjuvant hormonal therapy, whereas 56 patients had received prior adjuvant chemotherapy (22 patients anthracycline based (FAC/FEC), 34 patients non-anthracycline based (CMF)). All patients were routinely followed up as previously described (Martens et al, 2005; Meijer et al, 2008). The type of response to tamoxifen therapy was assessed according to standard criteria (Hayward et al, 1977; EORTC Breast Cancer Cooperative Group, 2000). Clinical benefit, defined as objective tumour response or no change lasting longer than 6 months, was observed in 185 patients $(62.5 \%) ; 13$ achieved complete remission, 38 partial remission and the remaining 134 patients experienced no change lasting longer than 6 months. A total of 111 patients did not experience clinical benefit (94 progressive disease and 17 no change less than or equal to 6 months). The median time to progression was 8.5 months. The median follow-up time after start of therapy of patients alive $(n=78)$ was 38.7 months.

For the analysis of the association of individual genes with tumour aggressiveness, 620 lymph node-negative (LNN) patients with $\mathrm{ER} \alpha$ protein-positive tumours were included (Supplementary Table S3). Of these patients, $52 \%$ had undergone breast-conserving lumpectomy and $100 \%$ node dissection. Adjuvant radiotherapy was administered to $58 \%$ of the patients, none of whom had received adjuvant systemic therapy. Distant recurrences were observed in 215 patients $(34.7 \%)$, and the median follow-up for patients alive $(n=427)$ was 93.4 months. A total of 193 deaths were recorded.

\section{Quantitative reverse transcription (RT) - PCR of breast tumours}

RNA isolation, cDNA synthesis, quality control checks and normalisation of data on a set of three reference genes (HPRT1, 
HBMS and B2M) were carried out as previously described (Sieuwerts et al, 2005; Meijer et al, 2008). Real-time quantitative RT-PCR was performed using the Stratagene Mx3000P QPCR System (Agilent Technologies, Waldbronn, Germany), Assay-onDemand kits for CITED2 (Hs00366696_m1) and NCOR2 (Hs00196955_m1) from Applied Biosystems (Nieuwerkerk a/d IJssel, The Netherlands), and the ABsolute qPCR Low ROX master Mix from Abgene Ltd (Epsom, UK). Quantification of ESR1, PGR and MKI67 mRNA levels was performed as described (Sieuwerts et al, 2005, 2007).

\section{Statistical analyses}

For statistical computations, STATA statistical package 10.0 (STATA Corp., College Station, TX, USA) was used. Differences in levels between groups were assessed using the Mann-Whitney $U$-test or the Kruskal-Wallis test, including a Wilcoxon-type test for trend, when appropriate. In these tests, patient and tumour characteristics were used as grouping variables. The strength of the association between continuous variables was tested with Spearman's rank correlation $\left(r_{s}\right)$. To reduce skewness, most variables were log- or Box-Cox transformed. The Cox proportional hazards model was used to calculate the hazard ratio (HR) and its $95 \%$ confidence interval (CI) in the analyses of metastasis-free survival (MFS), overall survival (OS) and progression-free survival (PFS). MFS was defined as the time between surgical removal of the primary tumour and the first detection of a distant metastasis, as revealed after symptoms were reported by the patient, the occurrence of clinical signs or at regular follow-up. Death from any cause was considered an event for OS. For advanced patients treated with tamoxifen, PFS was defined as the time elapsed between initiation of tamoxifen therapy and the first detection of progression of the disease. The proportional hazards assumption was not violated for MFS, as verified by a test based on Schoenfeld residuals. The proportional hazards assumption was violated for PFS, but not when follow-up was censored at 9 months as described previously (Sieuwerts et al, 2005). Logistic regression analysis was used to examine the relation of mRNA levels with clinical benefit of tamoxifen therapy, and for the calculation of the Odds Ratio (OR) and its 95\% CI. A two-sided $P$-value of $<0.05$ was considered to be statistically significant.

\section{RESULTS}

\section{Gene expression profiles of tamoxifen-resistant cell lines} are very similar

As all tamoxifen-resistant cell lines generated by insertion mutagenesis were derived from a single parental cell line (Dorssers et al, 1993; Van Agthoven et al, 2009b), it was hypothesised that differences in gene expression profiles would reflect the underlying mechanisms by which the retrovirally targeted genes induced tamoxifen resistance. From a total of 69 out of 79 cell lines, highquality total RNA from two independent cell cultures was converted into double-stranded cDNA and amplified into aRNA with T7-RNA polymerase. Fluorophore-labelled probes of tamoxifenresistant cell lines were hybridised onto a $35 \mathrm{~K}$ oligonucleotide array containing approximately 28000 annotated human genes, and compared with a reference probe derived from a panel of stable cell lines (Jansen et al, 2005). Our tamoxifen-resistant cell line panel showed clearly different gene expression patterns when compared with oestrogen-stimulated or tamoxifen-arrested parental ZR-75-1 cells (not shown).

Among the tamoxifen-resistant cell lines, unsupervised hierarchical clustering revealed very similar expression profiles (Supplementary Figure S1, 15376 genes) and did not group the bulk of cell lines belonging to a particular cVIS (Van Agthoven et al, 2009b). Only cell lines with a viral integration in NCOR2 were mostly positioned in close proximity within the dendrogram (Supplementary Figure S1, not indicated).

Subsequently, a class comparison analysis in which cell lines were organised according to the presence of a retrovirus in the same chromosomal region (Van Agthoven et al, 2009b) was performed. Between cell lines with an integration near BCAR1 or $B C A R 3$, very few differences were observed, in accordance with the results of our previous analysis of BCAR1- or BCAR3-transfected cells (Dorssers et al, 2005). Therefore, these cell lines were combined and used as the reference group for class comparison with each of the other groups of cell lines. All genes showing significant differences $(P<0.001 ; N=1106$, Supplementary Table S1) were pooled. After excluding genes showing a dye bias, 251 spots (representing 194 unique annotated genes) were left for hierarchical clustering analysis. The cell lines were organised into groups having a retroviral integration in the same chromosomal region (Figure 1 and Supplementary Figure S2). Cell lines belonging to the NCOR2 group showed the most prominent differences, having a higher expression of many genes, compared with the other tamoxifen-resistant cell lines. The retroviral target gene in the integration locus (NCOR2) was robustly upregulated in these cell lines (Figure 1, most right arrow). In agreement with the increased expression, western blot analysis confirmed that NCOR2 protein levels were increased in these cell lines (Supplementary Figure S3). The cell lines with an integration in the CITED2 locus also showed an altered expression of several genes, including strongly increased levels of the targeted CITED2 gene (Figure 1). This is in agreement with the previously established overexpression of CITED2 mRNA and protein in these cell lines (Van Agthoven et al, 2009b). Individual cell lines with a retroviral integration near $A K T 2$ or TRERF1 showed different expression patterns, suggesting clonal variation (Figure 1). Cell lines with integrations within cVIS5, 7, 10 or 11 (for which the responsible target genes have not yet been established (Van Agthoven et al, 2009b)) and cell lines lacking a common virus integration site did not show strongly different expression patterns (Supplementary Figure S2). Our class comparison analyses revealed a novel target gene (TSHZ1) in the cVIS6 locus, which was sevenfold upregulated as a consequence of virus integration (Supplementary Figure S2, arrow), but in this cell line, global gene expression was only minimally changed.

From these results, we conclude that in many cell lines, the gene causative for oestrogen independency did not impose a distinct and permanent expression phenotype. Only the virus integrations near NCOR2 and CITED2 caused a shift in gene expression.

\section{NCOR2 gene signature correlates with molecular subtypes in ER-positive breast cancer patients}

To analyse the clinical relevance of 171 genes differentially expressed in cell lines with a retroviral integration in NCOR2, compared with cell lines with an integration in BCAR1 and BCAR3 (Supplementary Table S2), we performed hierarchical clustering of the expression data from our series of 221 ER-positive breast tumours of LNN patients who did not receive adjuvant systemic therapy (Wang et al, 2005). Surprisingly, hierarchical clustering (Supplementary Figure S4a, Supplementary Information) of these genes resulted in a sample dendrogram, which showed a strong correlation with the molecular subtypes of these tumours (Perou et al, 2000; Smid et al, 2008). A detailed inspection showed that one branch consisted of tumours belonging to the normal-like and ERBB2 subtypes and nearly half of the tumours of luminal A-type (group A), whereas the two other groups contained tumours predominantly belonging to the luminal A- or B subtype (groups B and C). Patients with tumours belonging to cluster group A showed a prolonged MFS when compared with the MFS of the other two groups of patients (Supplementary Figure S4b). 


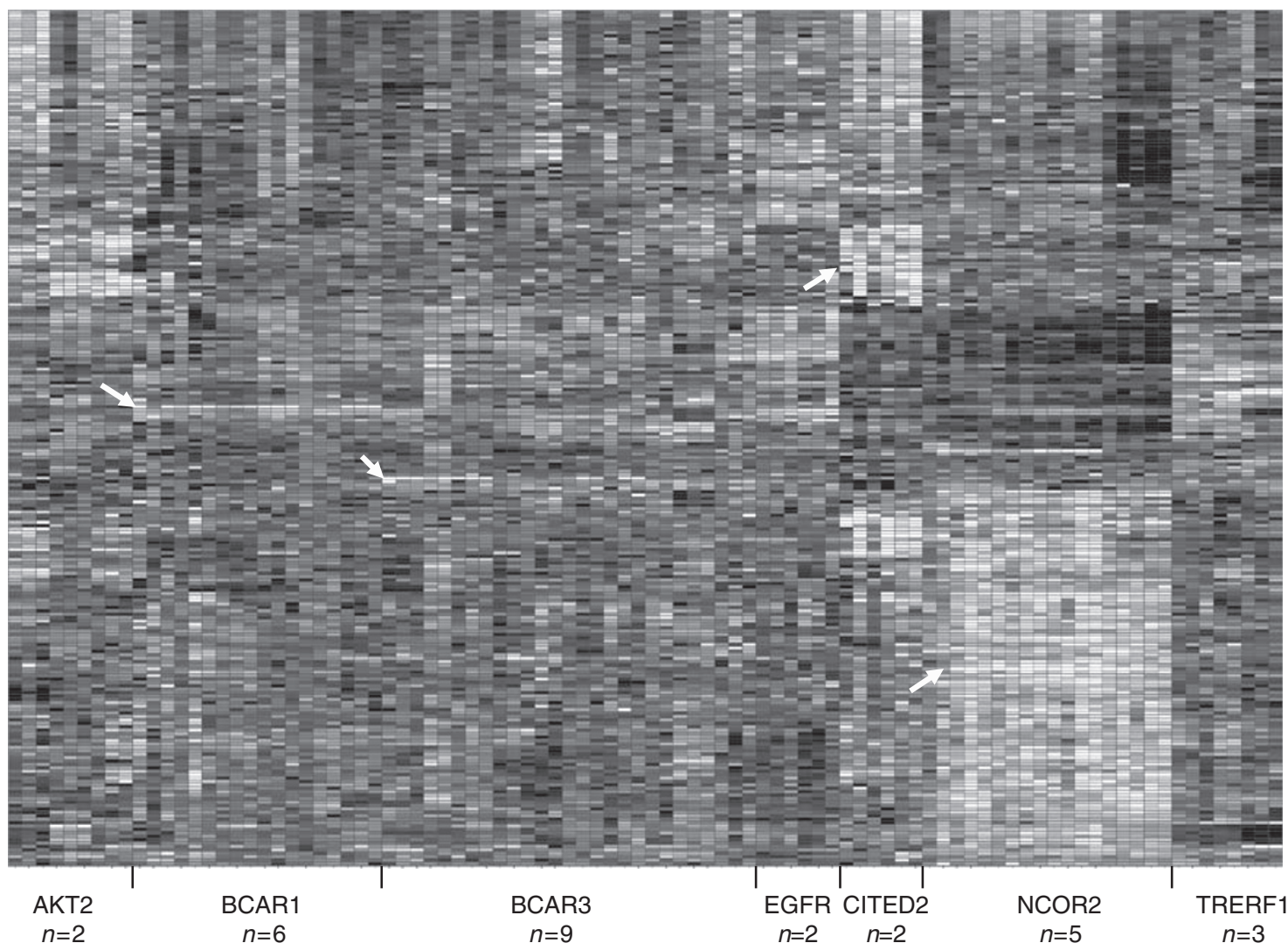

Figure I Hierarchical clustering of 25 I genes in tamoxifen-resistant breast cancer cell lines. Cell lines (three hybridisations each) were grouped together according to the location of the retrovirus in the cellular genome (columns). The number of different cell lines in a group is indicated below the name. Genes (rows) were selected by class comparison analysis and clustering was performed using the unweighted pair-group method with arithmetic mean in Spotfire. Gene expression above the mean is shown in white, that below the mean is indicated in black. Target genes in the integration loci are marked with arrows (from left to right: BCARI, BCAR3, CITED2 and NCOR2). The order of the genes, their names and identifiers are provided in Supplementary Table SI.

\section{Role of CITED2 and NCOR2 in breast cancer aggressiveness and tamoxifen resistance}

Given the impact of the viral integrations within NCOR2 and CITED2 on the overall mRNA expression in our cell model, we established their relationships with clinical parameters reflecting tamoxifen resistance and tumour aggressiveness. The mRNA levels of these two genes were determined in primary ER $\alpha$-positive tumours by quantitative RT-PCR and normalised to three reference genes. A correlation was observed between NCOR2 and CITED2, NCOR2 and MKI67, and between CITED2 and ESR1 $\left(r_{\mathrm{s}}>0.20, \quad P<0.0001\right) \quad$ (Supplementary Table S4). Increasing CITED2 mRNA levels were correlated with older age and postmenopausal status. Lower NCOR2 levels correlated with a higher grade (Supplementary Table S4).

For the analysis of association with tamoxifen treatment, 296 patients who received tamoxifen as first-line treatment for advanced disease (Supplementary Table S3) were included. In the univariate logistic regression analysis, high CITED2 mRNA levels were significantly associated with clinical benefit, both as a continuous ( $\mathrm{OR}=1.34, P=0.028$, Table 1$)$ and as a categorised variable (median, $\mathrm{OR}=2.20, P=0.001$ ). In multivariate analyses including the traditional predictive factors (that is, age and menopausal status at the start of tamoxifen therapy, disease-free interval, dominant site of relapse and ESR1 and PGR mRNA levels), high CITED2 levels remained significantly associated with clinical benefit (Table 1). Continuous CITED2 mRNA levels were of borderline significance for PFS. When divided into two equally sized groups, high levels of CITED2 mRNA were associated with favourable PFS, independently of traditional predictive factors
(Table 1). In contrast, NCOR2 mRNA levels as a continuous or as a categorised variable were not significantly associated with clinical benefit or PFS (Table 1). The results of the multivariate analyses with adjuvant chemotherapy as an additional variable showed that the estimates of the coefficients of individual genes were similar.

For the analysis of tumour aggressiveness, 620 ER $\alpha$-positive tumours of LNN patients who did not receive any systemic adjuvant treatment were included (Supplementary Table S3). In the analysis of MFS and OS, high levels of NCOR2 mRNA (both as a continuous and categorised variable, Table 2) were associated with a favourable outcome. The Kaplan-Meier analysis visualises the different outcomes of patients stratified according to the median level of NCOR2 (Figure 2A). In a multivariate analysis including traditional prognostic factors (age, menopausal status, tumour size, grade and ESR 1 and PGR mRNA levels), NCOR2 mRNA levels were significantly associated with a favourable MFS (median, $\mathrm{HR}=0.68, P=0.006$ ) and OS (Table 2). The analysis of CITED2 showed similar results. High levels of CITED2, both as a continuous and categorised variable, were significantly associated with prolonged MFS (Table 2). Kaplan-Meier curves illustrate the different outcomes for patients stratified according to the median CITED2 mRNA level (Figure 2B). These associations with MFS were independent of the classical prognostic factors $(\mathrm{HR}=0.71$, $P=0.017$, Table 2).

\section{DISCUSSION}

Insertion mutagenesis with retroviruses is a powerful tool to identify genes involved in sensitivity to anti-cancer agents. With 
Table I Progression-free survival (PFS) and clinical benefit after first-line tamoxifen treatment of 296 patients with ER+ primary breast tumours

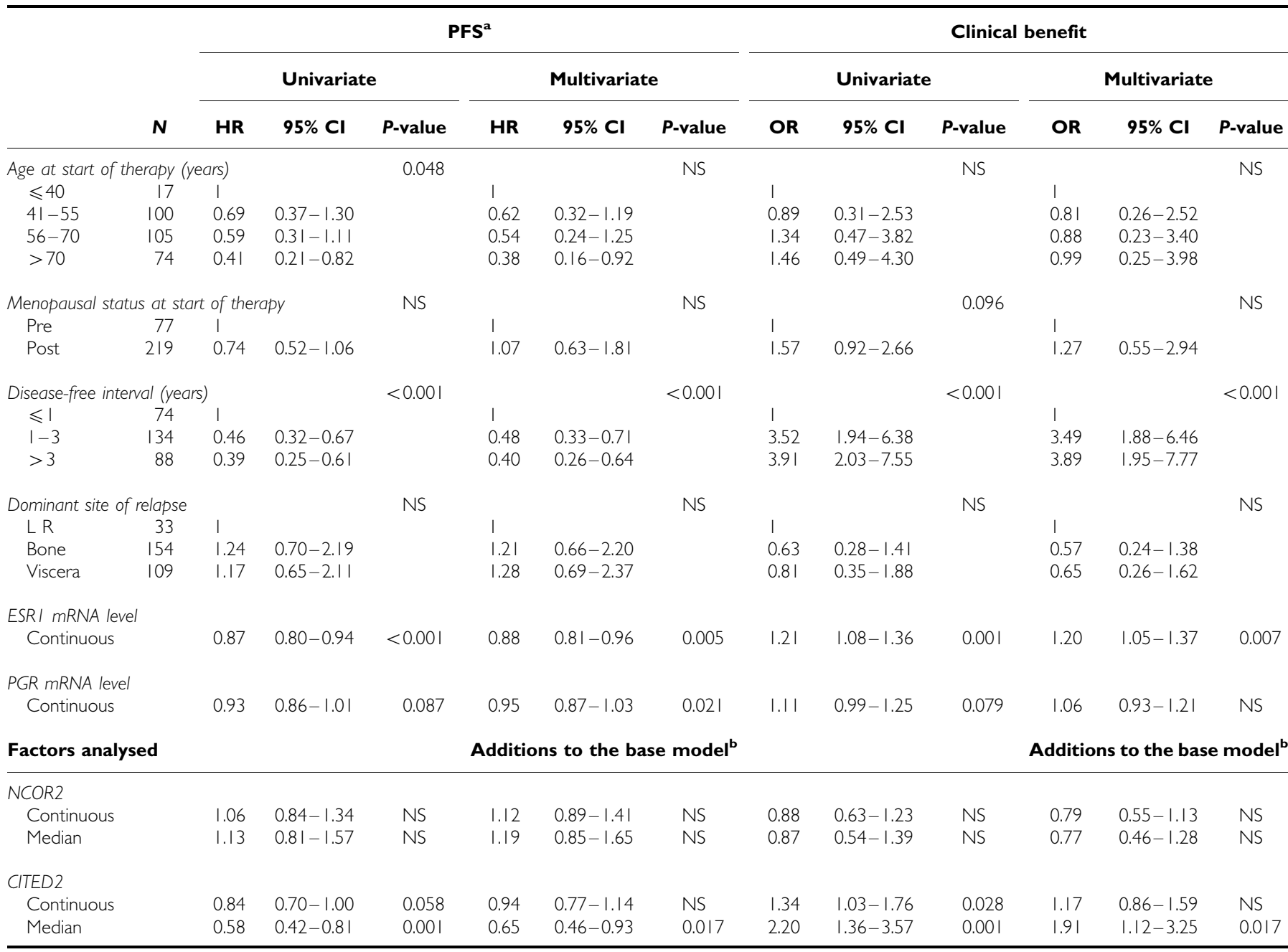

Abbreviations: $\mathrm{Cl}=$ confidence interval; $\mathrm{HR}=$ hazard ratio; $\mathrm{NS}=P$-values $>0.10 ; \mathrm{LR}=$ local regional; $\mathrm{OR}=$ odds ratio. ${ }^{\text {apFS }}$ was censored at 9 months, to avoid violation of the proportional hazards assumption. ' $F$ actors were separately introduced to the base multivariate model that included the factors age, menopausal status, disease-free interval, dominant site of relapse, ESRI and PGR mRNA levels.

this approach, we have been able to identify several genes conferring tamoxifen resistance in vitro (Van Agthoven et al, 1998, 2009b; Brinkman et al, 2000). To obtain a better insight into the mechanisms by which these genes induce tamoxifen resistance, we assessed whether differences in gene expression patterns existed between the different groups of tamoxifen-resistant cell lines. We found that most groups of cell lines showed a very similar pattern of gene expression, but that cell lines with a retroviral integration near NCOR2 or CITED2 showed a different gene expression profile. NCOR2 and CITED2 both function as regulators of transcription and therefore altered gene expression patterns could be expected by their deregulation. In contrast, other nuclear regulators (such as TRERF1), did not significantly change the expression profile. Importantly, for some groups of cell lines (for example, those with insertions near the AKT2 gene), differences in gene expression patterns were observed among the independently derived cell lines, suggesting clonal variations not related to the specific target gene. These observations imply that the changes in gene expression in unique cell lines not belonging to a cVIS cannot be interpreted as the consequence of the specific retroviral integration event. Our results strongly suggest that, although the targeted genes had a crucial role in the establishment of the resistant phenotype (Van Agthoven et al, 1998, 2009b;
Brinkman et al, 2000), ultimately these isogenic cell lines developed a common gene expression programme compatible with growth in the presence of tamoxifen. Additional hybridisation experiments involving transfectants with an inducible expression are required to further resolve the gene expression differences caused by the action of these genes and the underlying resistance pathways (Creighton et al, 2008). An alternative explanation may be that the deregulation of most targeted genes only caused posttranscriptional modifications, such as differences in the activation state of important signalling proteins, without affecting their mRNA levels. Such events cannot be measured by gene expression profiling but need to be assessed using other techniques (Korf et al, 2008; Schuchardt and Borlak, 2008; Speer et al, 2008).

The analysis of the expression data of the gene set associated with a retroviral integration within NCOR2 in our cell model identified patients with $\mathrm{ER} \alpha$-positive breast cancer with different MFS (Supplementary Figure S4). The best-performing group of patients revealed by this gene signature had tumours predominantly of the luminal A, normal-like or ERBB2 molecular subtypes. These findings suggest that the genes associated with NCOR2 activation in our cell model correlate with the well-established molecular breast cancer subtypes (Perou et al, 2000) and thereby may provide prognostic information for $\mathrm{ER} \alpha$-positive breast cancer. 
Table 2 Metastasis-free survival (MFS) and overall survival (OS) of 620 lymph node-negative patients with ER+ primary breast tumours

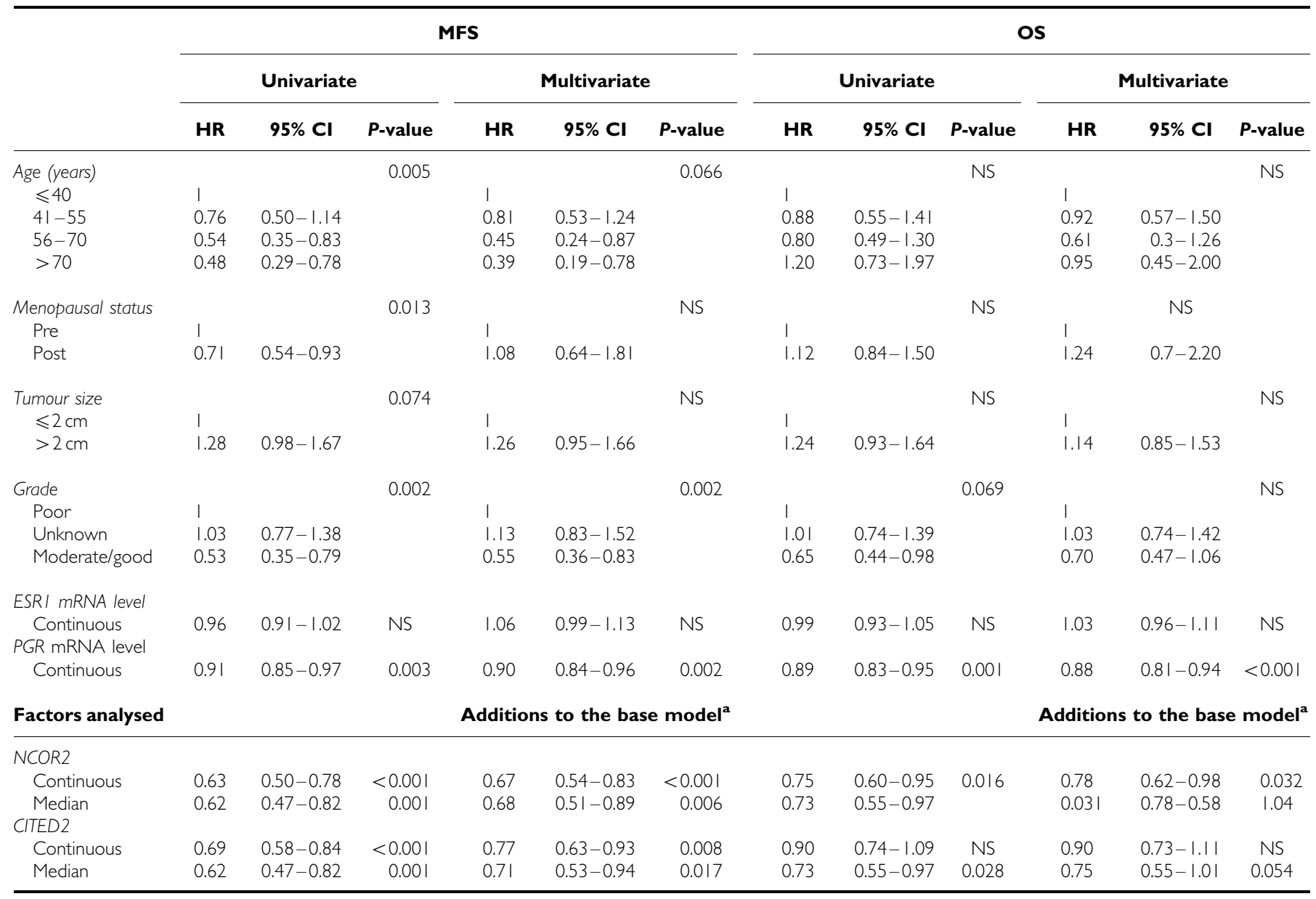

Abbreviations: $\mathrm{Cl}=$ confidence interval; $\mathrm{HR}=$ hazard ratio; $\mathrm{NS}=P$-value $>0.10 .{ }^{\mathrm{a}}$ Factors were separately introduced to the base multivariate model that included the factors age, menopausal status, tumour size, grade, ESRI and PGR mRNA levels.

As viral integrations in both NCOR2 and CITED2 yielded differences in gene expression patterns in our cell model, we quantified their mRNA levels in breast cancer tissues to further investigate the role of these two genes in tumour aggressiveness and resistance to tamoxifen. Our results showed that in LNN patients with ER $\alpha$-positive primary tumours who had not received systemic adjuvant treatment, high mRNA levels of NCOR2 and CITED2 were associated with a longer MFS independently of the traditional prognostic factors. Preliminary analyses in a subset of 120 patients for whom the molecular breast cancer subtype was known suggest that NCOR2 and CITED2 mRNA levels are particularly prognostic in patients with luminal A tumours, but not luminal B tumours (data not shown). In addition to its association with tumour aggressiveness, high levels of CITED2 mRNA were also significantly associated with clinical benefit of tamoxifen treatment in advanced breast cancer independently of the traditional predictive markers including adjuvant chemotherapy. This finding further emphasises the role of CITED2 in tamoxifen resistance.

NCOR2 participates in a co-repressor complex resulting in chromatin condensation and may also modulate ligand dependency of hormone receptors and contribute to oestrogen independency (Shou et al, 2004; Perissi and Rosenfeld, 2005). Furthermore, NCOR2 was shown to be a key regulator of neuronal stem cell differentiation by the repression of a specific histone demethylase (Jepsen et al, 2007). In a recent study by Green et al (2008), immunohistochemical analyses of tissue microarrays have indicated that moderate/high levels of NCOR2 protein, as found in $16.7 \%$ of tumours, are associated with poor prognosis of breast cancer patients. The differences in patient outcome, compared with the findings in our study, may be explained by the different targets measured (mRNA vs protein) and/or the different composition of patient groups. The study population explored by Green et al (2008) consisted of both ER $\alpha$-negative and -positive tumours, patients with lymph node-positive and -negative disease, whereas patients received adjuvant systemic treatment according to their Nottingham Prognostic Index. In contrast, our study population is a homogeneous set of ER $\alpha$-positive tumours of LNN patients who did not receive adjuvant systemic therapy, which allowed the assessment of the natural course of the disease. The importance of the selection of study groups is illustrated by the fact that we did not observe a relationship between NCOR2 mRNA levels and MFS in patients with $\mathrm{ER} \alpha$-negative tumours (data not shown), contrasting with our findings in ER $\alpha$-positive tumours (Table 2). It is noteworthy that the association of high NCOR2 levels with a favourable outcome in breast cancer patients seems to be in conflict with our cell line data, which showed increased NCOR2 mRNA and protein levels in tamoxifen-resistant cell lines (Figure 1 and Supplementary Figure S3). As we were unable to confirm the dominant role of NCOR2 in our cell model (Van Agthoven et al, 2009b) and did not establish an association with tamoxifen resistance, it is premature to speculate about mechanistic differences.

For CITED2, no information regarding the outcome of breast cancer patients was available. Its family member, CITED4, has 


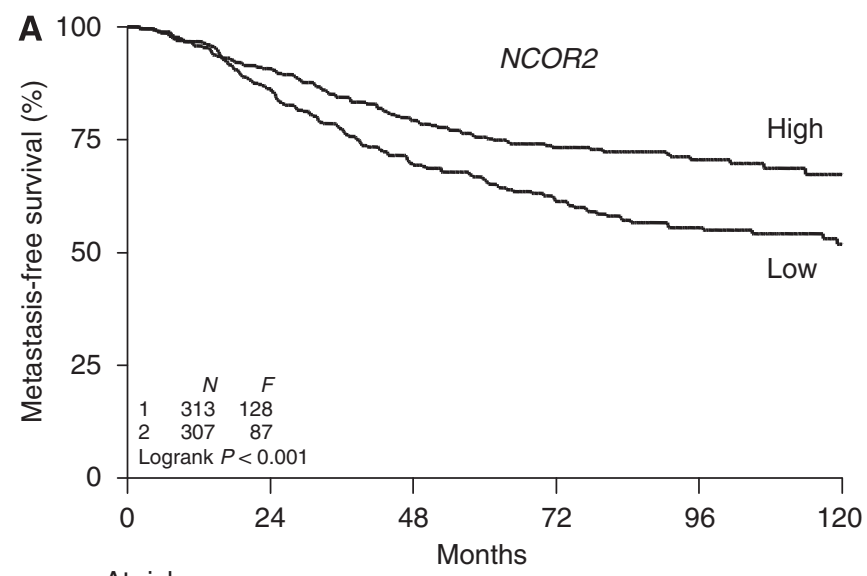

At risk:

1313

259

191

137

94

43

2307

270

227

174

104

37

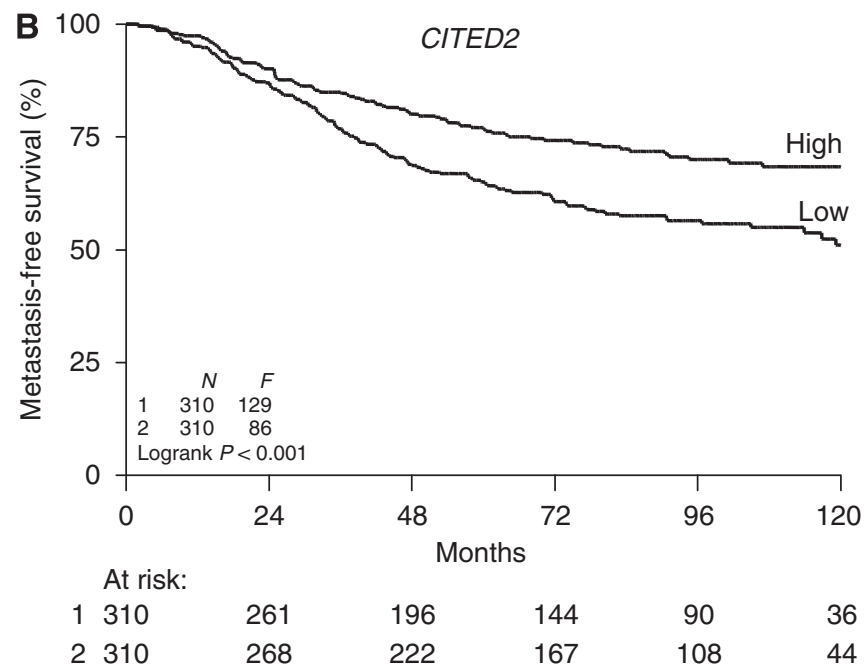

Figure 2 Metastasis-free-survival of 620 lymph node-negative patients with ER $\alpha$-positive breast cancer. Kaplan-Meier curves for MFS for subgroups of patients as a function of the NCOR2 (A) or CITED2 (B) mRNA levels of primary tumours. Patients were divided into two groups having primary tumours with high (above median) or low mRNA levels. The $y$ axis shows the percentage of patients without distant metastasis. Patients at risk (i.e., without event and not censored) at 24-month intervals are indicated. $N$, number of patients; $F$, number of patients with distant recurrences.

been analysed in breast tumours and was found to be associated with HIF $1 \alpha$ expression and to be either lost or translocated into the cytoplasm during tumour progression (Fox et al, 2004). CITED2 acts as a transcriptional co-factor and may regulate HIF1stimulated apoptosis through FOXO3a (Bakker et al, 2007).

\section{REFERENCES}

Ali S, Coombes RC (2002) Endocrine-responsive breast cancer and strategies for combating resistance. Nat Rev Cancer 2: 101-112

Bai L, Merchant JL (2007) A role for CITED2, a CBP/p300 interacting protein, in colon cancer cell invasion. FEBS Lett 581: 5904-5910

Bakker WJ, Harris IS, Mak TW (2007) FOXO3a is activated in response to hypoxic stress and inhibits HIF1-induced apoptosis via regulation of CITED2. Mol Cell 28: $941-953$

Brinkman A, Van der Flier S, Kok EM, Dorssers LCJ (2000) BCAR1, a human homologue of the adapter protein p130Cas and antiestrogen resistance in breast cancer cells. J Natl Cancer Inst 92: 112 - 120
CITED2 expression is regulated by protein arginine methyltransferases, which modulate histone and chromatin proteins (Kleinschmidt et al, 2008). Loss of CITED2 has been implicated in restored sensitivity to platinum compounds in resistant ovarian cancer cells (Yanagie et al, 2009) and in increased invasiveness in a colon cancer model (Bai and Merchant, 2007). In line with these observations, reduced CITED2 mRNA levels are a marker of poor prognosis in breast cancer patients. In contrast, in our cell line model, it was suggested that overexpression caused tamoxifen resistance (Figure 1). Our transfection experiments have not yet been successful in confirming this speculation (Van Agthoven et al, 2009b).

In summary, our functional genetic screen by retroviral insertion mutagenesis has identified several genes that are causal or strongly implicated in anti-oestrogen resistance of breast cancer cells. Although all tamoxifen-resistant cell lines obtained through this approach showed a gene expression profile distinct from parental cells, among these tamoxifen-resistant cell lines, expression patterns were nearly indistinguishable from each other. In these cases, alteration of signalling cascades leading to tamoxifen resistance may occur at the post-transcriptional level, such as protein activation status, which is not translated into different gene expression patterns. In contrast, cell lines with viral integrations affecting NCOR2 and CITED2 expression, showed different gene expression patterns when compared with the other tamoxifenresistant cell lines. Importantly, our experiments have shown that NCOR2, CITED2 and other genes previously revealed through functional screening (Van Agthoven et al, 2009a) are implicated in breast cancer outcome and therefore bear clinical relevance. On the basis of these results, further studies into the mechanisms of tamoxifen resistance of these cell line models are warranted to identify novel targets for therapy, as well as novel prognostic and predictive markers. Ultimately, this could result in improved outcome to endocrine therapy and to a more individualised management of breast cancer patients.

\section{ACKNOWLEDGEMENTS}

We thank Thecla van Agthoven, Ingrid de Vries, Sietske Tuinman, Roya Sarwari and Najat Azaouagh for their support. The contribution of Ron Kerkhoven and colleagues of the CMF-NKI is gratefully acknowledged. We thank Marcia Godinho and Maxime Look for critical reading of the paper. For stimulating discussions and support, we are indebted to our colleagues at the Josephine Nefkens Institute. This study was supported by grants from the Dutch Cancer Society (DDHK96-1245, 99-1883 \& 2002-2675), the Susan G Komen Breast Cancer Foundation (BCTR0100675 \& 0402594), the Association for International Cancer Research (04-148) and the Netherlands Genomic Initiative (NGI)/Netherlands Organization for Scientific Research (NWO).

Supplementary Information accompanies the paper on British Journal of Cancer website (http://www.nature.com/bjc)
Clarke R, Liu MC, Bouker KB, Gu Z, Lee RY, Zhu Y, Skaar TC, Gomez B, O'Brien K, Wang Y, Hilakivi-Clarke LA (2003) Antiestrogen resistance in breast cancer and the role of estrogen receptor signaling. Oncogene 22: $7316-7339$

Creighton CJ, Massarweh S, Huang S, Tsimelzon A, Hilsenbeck SG, Osborne CK, Shou J, Malorni L, Schiff R (2008) Development of resistance to targeted therapies transforms the clinically associated molecular profile subtype of breast tumor xenografts. Cancer Res 68: 7493-7501

Dorssers LCJ, Van Agthoven T, Brinkman A, Veldscholte J, Smid M, Dechering KJ (2005) Breast cancer oestrogen independence mediated by 
BCAR1 or BCAR3 genes is transmitted through mechanisms distinct from the oestrogen receptor signalling pathway or the epidermal growth factor receptor pathway. Breast Cancer Res 7: R82 - R92

Dorssers LCJ, Van Agthoven T, Dekker A, Van Agthoven TLA, Kok EM (1993) Induction of antiestrogen resistance in human breast cancer cells by random insertional mutagenesis using defective retroviruses: Identification of bcar-1, a common integration site. Mol Endocrinol 7: $870-878$

Early Breast Cancer Trialists' Collaborative Group (2005) Effects of chemotherapy and hormonal therapy for early breast cancer on recurrence and 15-year survival: an overview of the randomised trials. Lancet 365: 1687-1717

Edgar R, Domrachev M, Lash AE (2002) Gene expression omnibus: NCBI gene expression and hybridization array data repository. Nucleic Acids Res 30: $207-210$

EORTC Breast Cancer Cooperative Group (2000) Manual for Clinical Research and Treatment in Breast Cancer. pp 116-117. Excerpta Medical: Almere, The Netherlands

Foekens JA, Portengen H, van Putten WL, Peters HA, Krijnen HL, AlexievaFigusch J, Klijn JG (1989) Prognostic value of estrogen and progesterone receptors measured by enzyme immunoassays in human breast tumor cytosols. Cancer Res 49: $5823-5828$

Fox SB, Braganca J, Turley H, Campo L, Han C, Gatter KC, Bhattacharya S, Harris AL (2004) CITED4 inhibits hypoxia-activated transcription in cancer cells, and its cytoplasmic location in breast cancer is associated with elevated expression of tumor cell hypoxia-inducible factor 1alpha. Cancer Res 64: 6075-6081

Green AR, Burney C, Granger CJ, Paish EC, El-Sheikh S, Rakha EA, Powe DG, Macmillan RD, Ellis IO, Stylianou E (2008) The prognostic significance of steroid receptor co-regulators in breast cancer: corepressor NCOR2/SMRT is an independent indicator of poor outcome. Breast Cancer Res Treat 110: 427-437

Hayward JL, Carbone PP, Heuson JC, Kumaoka S, Segaloff A, Rubens RD (1977) Assessment of response to therapy in advanced breast cancer: a project of the Programme on Clinical Oncology of the International Union Against Cancer, Geneva, Switserland. Cancer 39: $1289-1293$

Howell A (2006) Pure oestrogen antagonists for the treatment of advanced breast cancer. Endocr Relat Cancer 13: 689-706

Hurtado A, Holmes KA, Geistlinger TR, Hutcheson IR, Nicholson RI, Brown M, Jiang J, Howat WJ, Ali S, Carroll JS (2008) Regulation of ERBB2 by oestrogen receptor-PAX2 determines response to tamoxifen. Nature 456: 663-666

Iorns E, Turner NC, Elliott R, Syed N, Garrone O, Gasco M, Tutt AN, Crook T, Lord CJ, Ashworth A (2008) Identification of CDK10 as an important determinant of resistance to endocrine therapy for breast cancer. Cancer Cell 13: $91-104$

Jaiyesimi IA, Buzdar AU, Decker DA, Hortobagyi GN (1995) Use of tamoxifen for breast cancer: Twenty-eight years later. J Clin Oncol 13: $513-529$

Jansen MP, Foekens JA, van Staveren IL, Dirkzwager-Kiel MM, Ritstier K, Look MP, Meijer-van Gelder ME, Sieuwerts AM, Portengen H, Dorssers LC, Klijn JG, Berns EM (2005) Molecular classification of tamoxifenresistant breast carcinomas by gene expression profiling. J Clin Oncol 23: $732-740$

Jansen MP, Sieuwerts AM, Look MP, Ritsier K, meijer-Van Gelder ME, van Staveren IL, Klijn JG, Foekens JA, Berns EM (2007) HOXB13-to-IL17BR expression ratio is related with tumor aggressiveness and response to tamoxifen of recurrent breast cancer: a retrospective study. J Clin Oncol 25: $662-668$

Jepsen K, Solum D, Zhou T, McEvilly RJ, Kim HJ, Glass CK, Hermanson O, Rosenfeld MG (2007) SMRT-mediated repression of an H3K27 demethylase in progression from neural stem cell to neuron. Nature 450: $415-419$

Jordan VC (1995) Third Annual William L McGuire Memorial Lecture Studies on the estrogen receptor in breast cancer -20 years as a target for the treatment and prevention of cancer. Breast Cancer Res Treat 36: $267-285$

Kleinschmidt MA, Streubel G, Samans B, Krause M, Bauer UM (2008) The protein arginine methyltransferases CARM1 and PRMT1 cooperate in gene regulation. Nucleic Acids Res 36: 3202-3213

Korf U, Henjes F, Schmidt C, Tresch A, Mannsperger H, Lobke C, Beissbarth T, Poustka A (2008) Antibody microarrays as an experimental platform for the analysis of signal transduction networks. Adv Biochem Eng Biotechnol 110: 153-175
Martens JW, Nimmrich I, Koenig T, Look MP, Harbeck N, Model F, Kluth A, Bolt-de Vries J, Sieuwerts AM, Portengen H, Meijer-Van Gelder ME, Piepenbrock C, Olek A, Hofler H, Kiechle M, Klijn JG, Schmitt M, Maier S, Foekens JA (2005) Association of DNA methylation of phosphoserine aminotransferase with response to endocrine therapy in patients with recurrent breast cancer. Cancer Res 65: 4101-4117

McShane LM, Altman DG, Sauerbrei W, Taube SE, Gion M, Clark GM, Statistics Subcommittee of NCIEWGoCD (2006) REporting recommendations for tumor MARKer prognostic studies (REMARK). Breast Cancer Res Treat 100: 229-235

Meester-Smoor MA, Janssen MJ, Grosveld GC, de Klein A, van IWF, Douben H, Zwarthoff EC (2008) MN1 affects expression of genes involved in hematopoiesis and can enhance as well as inhibit RAR/RXRinduced gene expression. Carcinogenesis 29: 2025-2034

Meijer D, Jansen MPHM, Look MP, Ruigrok-Ritstier K, Van Staveren IL, Sieuwerts AM, Van Agthoven T, Foekens JA, Dorssers LCJ, Berns EMJJ (2009) TSC22D1 and PSAP predict clinican outcome of tamoxifen treatment in patients with recurrent breast cancer. Breast Cancer Res Treat 113: 253-260

Meijer D, Sieuwerts AM, Look MP, Van Agthoven T, Foekens JA, Dorssers LCJ (2008) Fibroblast growth factor receptor 4 predicts failure on tamoxifen therapy in patients with recurrent breast cancer. Endocr Relat Cancer 15: 101 - 111

Mouridsen H, Gershanovich M, Sun Y, Perez-Carrion R, Boni C, Monnier A, Apffelstaedt J, Smith R, Sleeboom HP, Jaenicke F, Pluzanska A, Dank M, Becquart D, Bapsy PP, Salminen E, Snyder R, Chaudri-Ross H, Lang R, Wyld P, Bhatnagar A (2003) Phase III study of letrozole versus tamoxifen as first-line therapy of advanced breast cancer in postmenopausal women: analysis of survival and update of efficacy from the International Letrozole Breast Cancer Group. J Clin Oncol 21: 2101 - 2109

Nabholtz JM, Buzdar A, Pollak M, Harwin W, Burton G, Mangalik A, Steinberg M, Webster A, von Euler M (2000) Anastrozole is superior to tamoxifen as first-line therapy for advanced breast cancer in postmenopausal women: results of a North American multicenter randomized trial. Arimidex Study Group. J Clin Oncol 18: $3758-3767$

Osborne CK (1998) Tamoxifen in the treatment of breast cancer. N Engl J Med 339: $1609-1618$

Osborne CK, Shou J, Massarweh S, Schiff R (2005) Crosstalk between estrogen receptor and growth factor receptor pathways as a cause for endocrine therapy resistance in breast cancer. Clin Cancer Res 11: $865 s-870 s$

Paridaens R, Dirix L, Lohrisch C, Beex L, Nooij M, Cameron D, Biganzoli L, Cufer T, Duchateau L, Hamilton A, Lobelle JP, Piccart M (2003) Mature results of a randomized phase II multicenter study of exemestane versus tamoxifen as first-line hormone therapy for postmenopausal women with metastatic breast cancer. Ann Oncol 14: 1391-1398

Perissi V, Rosenfeld MG (2005) Controlling nuclear receptors: the circular logic of cofactor cycles. Nat Rev Mol Cell Biol 6: 542-554

Perou CM, Sorlie T, Eisen MB, van de Rijn M, Jeffrey SS, Rees CA, Pollack JR, Ross DT, Johnsen H, Akslen LA, Fluge O, Pergamenschikov A, Williams C, Zhu SX, Lonning PE, Borresen-Dale AL, Brown PO, Botstein D (2000) Molecular portraits of human breast tumours. Nature 406: $747-752$

Riggins RB, Schrecengost RS, Guerrero MS, Bouton AH (2007) Pathways to tamoxifen resistance. Cancer Lett 256: 1-24

Schuchardt S, Borlak J (2008) Quantitative mass spectrometry to investigate epidermal growth factor receptor phosphorylation dynamics. Mass Spectrom Rev 27: 51-65

Shou J, Massarweh S, Osborne CK, Wakeling AE, Ali S, Weiss H, Schiff R (2004) Mechanisms of tamoxifen resistance: increased estrogen receptorHER2/neu cross-talk in ER/HER2-positive breast cancer. J Natl Cancer Inst 96: $926-935$

Sieuwerts AM, Look MP, Meijer-van Gelder ME, Timmermans M, Trapman AM, Garcia RR, Arnold M, Goedheer AJ, de Weerd V, Portengen H, Klijn JG, Foekens JA (2006) Which cyclin E prevails as prognostic marker for breast cancer? Results from a retrospective study involving 635 lymph node-negative breast cancer patients. Clin Cancer Res 12: 3319-3328

Sieuwerts AM, Meijer-van Gelder ME, Timmermans M, Trapman AM, Garcia RR, Arnold M, Goedheer AJ, Portengen H, Klijn JG, Foekens JA (2005) How ADAM-9 and ADAM-11 differentially from estrogen receptor predict response to tamoxifen treatment in patients with recurrent breast cancer: a retrospective study. Clin Cancer Res 11: $7311-7321$

Sieuwerts AM, Usher PA, Meijer-van Gelder ME, Timmermans M, Martens JW, Brunner N, Klijn JG, Offenberg H, Foekens JA (2007) Concentrations 
of TIMP1 mRNA splice variants and TIMP-1 protein are differentially associated with prognosis in primary breast cancer. Clin Chem 53: $1280-1288$

Smid M, Wang Y, Zhang Y, Sieuwerts AM, Yu J, Klijn JG, Foekens JA, Martens JW (2008) Subtypes of breast cancer show preferential site of relapse. Cancer Res 68: 3108-3114

Speer R, Wulfkuhle J, Espina V, Aurajo R, Edmiston KH, Liotta LA, Petricoin III EF (2008) Molecular network analysis using reverse phase protein microarrays for patient tailored therapy. Adv Exp Med Biol 610: $177-186$

Van Agthoven T, Sieuwerts AM, Meijer-Van Gelder ME, Look MP, Smid M, Veldscholte J, Sleijfer S, Foekens JA, Dorssers LCJ (2009a) Relevance of breast cancer antiestrogen resistance genes in human breast cancer progression and tamoxifen resistance. J Clin Oncol 27: $542-549$

Van Agthoven T, Van Agthoven TLA, Dekker A, Van der Spek PJ, Vreede L, Dorssers LCJ (1998) Identification of BCAR3 by a random search for genes involved in antiestrogen resistance of human breast cancer cells. EMBO J 17: 2799-2808

Van Agthoven T, Veldscholte J, Smid M, Van Agthoven TLA, Vreede L, Broertjes M, De Vries I, De Jong D, Sarwari R, Dorssers LCJ (2009b) Functional screen identifies genes associated with human breast cancer progression. Breast Cancer Res Treat 114: $23-30$

Wang Y, Klijn JG, Zhang Y, Sieuwerts AM, Look MP, Yang F, Talantov D, Timmermans M, Meijer-van Gelder ME, Yu J, Jatkoe T, Berns EM, Atkins D, Foekens JA (2005) Gene-expression profiles to predict distant metastasis of lymph-node-negative primary breast cancer. Lancet 365: $671-679$

Yanagie H, Hisa T, Ogata A, Miyazaki A, Nonaka Y, Nishihira T, Osada I, Sairennji T, Sugiyama H, Furuya Y, Kidani Y, Takamoto S, Takahashi H, Eriguchi M (2009) Improvement of sensitivity to platinum compound with siRNA knockdown of upregulated genes in platinum complex-resistant ovarian cancer cells in vitro. Biomed Pharmacother 63(8): $553-560$ 